\title{
Using Hierarchical Growth Modeling to Promote District Systematic Improvement in Ohio and Texas
}

\author{
Alex J. Bowers \\ Teachers College, Columbia University \\ Bowers@tc.edu
}

\author{
Xinyu Ni \\ Teachers College, Columbia University \\ xn2115@tc.columbia.edu
}

\author{
Jennifer Esswein \\ Education Northwest \\ Jennifer.Esswein@educationnorthwest.org
}

\begin{abstract}
:
The purpose of this study is to apply hierarchical linear growth modelling to district demographic and effectiveness data in the U.S. states of Ohio and Texas to identify districts that are significantly outperforming or underperforming their demographic and resource characteristics from the entire population of districts in a state. The study focuses on administrative panel data for the years 2006-2012 for all districts in Ohio $(\mathrm{n}=608)$ and $2005-2011$ for all districts in Texas $(\mathrm{n}=1028)$. Our findings indicate that: 1) Multiple district demographic variables and financial expenditures, such as enrollment, student ethnicity, district location, and general and school administration expenditures per pupil have a significant relationship to growth in district academic achievement; 2) we identified 32 significantly outperforming districts in Texas and 15 districts in Ohio; 3 ) we compare this identification system with state accountability indicators through a quadrant plot to provide a new framework for site selection in district effectiveness research, which has important implications for the policy and practice of re-envisioning school district effectiveness.
\end{abstract}

Keywords: School District, District Effectiveness Research (DER), Hierarchical Modeling, Longitudinal Studies, School Effectiveness Research (SER)

\section{INTRODUCTION:}

Over the past 30 years, the research and practice literature on the effects of school districts on student achievement has indicated that school district personnel practices can have a strong effect on individual and overall student, school and district achievement (Bryk, 2010; Elmore \& Burney, 1997; Honig, 2003, 2008; Leithwood, 2010; Purkey \& Smith, 1985). Additionally, as the United States national educational policy changes from rigid sanction rules and high pressure under No Child Left Behind (NCLB) to a more flexible and local capacity framework of the

${ }^{1}$ This document is a pre-print of the manuscript published in Leading Holistically: How Schools, Districts, and States Improve Systemically. Citation:

Bowers, A.J., Ni, X., Esswein, J. (2018) Using Hierarchical Growth Modeling to Promote District Systematic Improvement in Ohio and Texas. In Shaked, H., Schechter, C., Daly, A. (Eds.) Leading Holistically: How Schools, Districts, and States Improve Systemically (p.77-100). Routledge. https://www.taylorfrancis.com/books/e/9781351362191/chapt ers/10.4324\%2F9780203712184-5

2 Alex J. Bowers (bowers@tc.edu); Teachers College, Columbia University; $525 \mathrm{~W} .120^{\text {th }}$ Street, New York, New York 10027. ORCiD: 0000-0002-5140-6428
Every Student Succeeds Act (ESSA), it is important for researchers, practitioners, and policy-makers to consider school districts as the leverage point for bringing multiple financial and human capital components of the district to bear on district-level improvement, rather than an emphasis on school-by-school change as districts in the United States are comprised of systems of schools nested within the district community (Daly \& Finnigan, 2016). Indeed, while some school districts struggle to find success, others outperform peer districts that have similar context and demographic effects over long periods of time. However, previous research and practice has encountered obstacles in sampling and site-selection in what has been called District Effectiveness Research (DER) (Bowers, 2010). According to Trujillo $(2013,2015)$, the majority of studies in DER rely on convenience samples or districts with extremely high or low performance without considering district demographic characteristics, which makes it difficult to assess the external validity and generalizability of these research results.

Thus, in addressing these issues, the purpose of this study is to apply hierarchical linear growth modelling to all school districts in the states of Ohio and Texas in the United States of America to identify districts that significantly outperform or underperform their contexts, demographics, and resources in comparison to the rest of the system of districts across the population of a state. The study builds on the previous literature on system-level research at the district level to identify unusually effective school districts over time in three main ways. First, we applied the site-selection hierarchical longitudinal model (Bowers, 2008, 2010, 2015) in two different states, Ohio and Texas, each with very different educational histories and challenges, and we successfully identify outperforming districts, demonstrating the generalizability and practicability of this modeling framework in DER. Second, we propose the system-level district effectiveness analysis using data from every school district in a state (the system-level) which can then be used to bring together personnel from top districts to discuss what is idiosyncratic versus generalizable in their work in their districts and states in order to help other districts across the system improve. Third, we discuss how the outperforming districts identified from the model compare to the "excellent" districts as graded by each state accountability system to provide further suggestions on state evaluation systems.

Throughout this study we consider school districts as the central actor in a systems perspective, in which we draw on a central aspect of much of the recent research on the school district as being made up of not only a system of schools, but a system of central office personnel and school building leaders in addition to and in collaboration with the superintendent and elected school boards (Daly \& Finnegan, 2016; Honig, 2003, 2008; Honig \& 
Rainey, 2015). These researchers have argued for districts research to go beyond considering "the district" as a monolithic actor, and instead consider the work of the many different people throughout a school district that make it work. In the present study we expand on this conception, and examine districts within the broader system of school districts across two states, considering every district within the policy region, over long periods of time. From a systems-thinking perspective, this helps move the research from the previous "snapshot" single district or timepoint studies of the past research (Bowers, 2010, 2015; Trujillo, 2013, 2015) towards "a framework for seeing interrelationships rather than things, for seeing patterns of change rather than static snapshots" (Senge, 1990, p.68) and "seeing beyond what appear to be isolated and independent incidents to deeper patterns" (O’Conner \& McDermott, 1997, p7).

\section{BACKGROUND AND LITERATURE REVIEW:}

In the United States, public schools are nested within school districts, which makes the school district a unique unit for analysis in research and practice. A continual question within the research on school districts has looked to find unusually effective districts, known as district effectiveness research (DER), originating in the 1980s. In the early district effectiveness research (DER), researchers mainly focused on central office practices that were linked with school and district success as well as what characteristics were associated with successful school districts. For instance, Purkey and Smith (1985) argued that school districts could promote successful school reforms through several practices such as setting clear goals at the school level and providing coherent and organized staff development. Leithwood (2010) examined thirty-one previous studies on district effectiveness and summarized ten district characteristics that are mostly effective in promoting students' educational outcomes including setting instructional goals, promoting instructional improvement, and aligning multiple resources such as personnel policies and financial allocations. The majority of the research in DER indicates that school districts have a strong impact in promoting students' learning, advancing teaching quality, focusing on sustained school-level professional development and closing achievement gaps (Bowers, 2008; Bowers \& Lee, 2013; Bryk, 2010; Elmore, 1999; Firestone, 2005; Levin, 2012; Opfer, 2008; Honig, 2003, 2008). However, in a recent study (Chingos, Whitehurst, \& Gallaher, 2015) analyzing data from Florida and North Carolina fourth and fifth grades with a cross-sectional hierarchical linear model, the authors found that the district effect explained only a small amount of the variation in student achievement- with one standard deviation increase in district effectiveness associated with 0.07-0.14 standard deviation increase in student achievement in reading or mathematics for single years.

Nevertheless, across the DER literature, authors note that the study of school districts is a complicated concept, as an increasing amount of researchers agree that districts should not be considered as a monolithic concept of "the district", which oftentimes focuses on superintendent behavior, but rather instead, the district is an organizational and systems concept made up of multiple demographic, sociopolitical and technical elements, which vary in size, characteristics, conditions and context (Daly
\& Finnigan, 2012, 2016; Honig \& Rainey, 2015). Thus, building on this previous literature, we argue here that the DER literature should model district effects using a more dynamic and systemslevel perspective, rather than focus on single-year or "snapshot" research models (Bowers, 2010, 2015). First, there is a need to measure the effectiveness of districts through more dynamic and systematic ways, especially as the DER literature has noted that the definition of effectiveness ranges broadly from standardized test score performance, to student growth in test scores, to other outcomes, such as high school graduation and college-going to name just a few (Bowers, 2010, 2015). As a measure of collaborative efforts from the central office within school districts, the measurement of "district effectiveness" should reflect an index of multiple aspects of district school performance, such as student overall performance on different subjects from various grades as well as teacher effectiveness. However, as noted in the previous research (Trujillo, 2013; Bowers 2010), a majority of studies have relied on just English/reading or mathematics standardized state test scores to conceptualize "effectiveness". This thus unnecessarily overly restricts the definition of effectiveness.

Second, district effects happen over time, so it is important to conduct longitudinal studies to explore the improvement or change of district effects over multiple years. Specifically, as districts in the US have come under increasing accountability demands over the past 30 years (Ni, Bowers, \& Esswein, 2016), effective districts could serve as a key link between state-context policies and school day-to-day practices through developing "coherent instructional strategies" (Thompson, Sykes, \& Skrla, 2008) in which they bring together the multiple financial and human capital components of the district in service to promote overall systematic changes (Skrla, McKenzie, Scheurich, \& Dickerson, 2011). But such organizational improvements would happen continuously and slowly (Smylie, 2009), which cannot be detected through studies that rely on data from a single point in time. Thus, continuous examination through longitudinal studies is necessary to explore and reflect on the overall systematic changes within districts.

Third, researchers need to develop a systematic and comprehensive method to identify or define "effective districts" for in-depth follow-up qualitative studies by taking district demographic characteristics into account. As noted above, the goal of DER has historically been to identify unusually effective school districts, and then work to study those districts in comparison to districts at the average through in-depth qualitative studies to identify the practices and innovations that may lead to effectiveness at the district level in a state. However, as an organization composed of various resources and processes in the context of the community in which it is situated, school performance is historically strongly correlated with community demographics, such as poverty or wealth, as well as the proportion of students from historically disadvantaged backgrounds. Simply identifying highly effective districts from the ranking of a certain measurement, such as student academic achievement, without considering these types of unique district characteristics will identify only districts that are comparatively well-off. This is problematic when attempting to find the most 
effective districts, as organizations should not be penalized for variables that are outside of their control, such as student and community socio-economic status. This issue can be addressed through including all districts in a state in the analysis and statistically controlling for these demographic and context effects (Leithwood, 2010; Bowers, 2008, 2010, 2015).

In a series of longitudinal studies, Bowers (2008, 2010, 2015) detailed a site-selection model through applying a hierarchical linear growth modeling approach to all school districts in Ohio to identify districts that significantly outperform or underperform their background and demographics, while including sociopolitical and technical resources. These studies nested time within districts, and then modeled both the performance of each district in the first year of the model, as well as growth over time, examining which districts outperformed in overall performance as well as growth over the period, while controlling for background and context variables. In an attempt to examine the systematic changes for all districts in Ohio and address previous critiques, the statistical models relied on seven consecutive years of data including, demographic variables for each district, and a composite measure of district effectiveness - the Performance Index (PI) score - which is an aggregated measure of students' performance on state standard tests for reading, mathematics, science and social studies across grades 3 through 12 . The model successfully identified groups of outperforming school districts that achieved significant performance growth in comparison to the entire population of school districts in Ohio over an extended period of time. These districts were then identified by name, and deemed as having significantly outperformed the average district with similar demographic and context variables, and were then nominated for in-depth qualitative analysis with the purpose of comparing practices in outperforming school districts with the norm or the underperforming school districts. This site-selection strategy provides a potential way to examine systematic and dynamic district changes, generates knowledge that may help inform decision-making, and improves external validity for research studies in DER (Trujillo, 2013). Also, given that the model was conducted on two overlapping but different sets of years in the two studies (Bowers, 2010, 2015), this showed that the statistical model works successfully with different time periods within the single state of Ohio.

Nevertheless, Bowers' (2010) and (2015) studies are limited in three major aspects. First, the site-selection model has only been applied to Ohio to date and there is no evidence indicating whether the model will work in states having more districts and larger variance in demographic characteristics than Ohio. In the present study, we address this issue through replicating the analysis in Texas, which is a much larger state than Ohio in both population as well as number of districts and schools (over 1,000 districts in Texas compared to about 600 in Ohio), and Texas has a different set of state assessments than Ohio, their own set of education policies and laws and different state governments. Additionally, Texas is demographically and geographically a very different context from Ohio, as Ohio is a mid-western state in the industrial rust-belt of the US, while Texas is a large southern border state with a large and growing Hispanic/Latino population and a growing industrial base. Second, although previous studies have included average teacher salary in the model, more detailed financial expenditures haven't been considered, such as direct expenditures on instructional services by the district. Previous qualitative studies have indicated that central office personnel in effective districts are able to align multiple funding streams and financial components with the instructional goals of the district to address instructional and pedagogical improvement across all schools in the system (Bowers, 2008; Elmore \& Burney, 1997; Skrla, McKenzie, Scheurich, \& Dickerson, 2011; Thompson et al., 2008). Therefore, more savvy financial indicators in addition to teacher average salary are needed, as if a district is outperforming context and demographic variables as well as financial variables of the districts at comparable averages in a state, then an outperforming district in the model could be considered as effective, equitable and efficient. Third, the model successfully identifies groups of outperforming districts compared to the majority of districts at the norm. This is important as past DER studies provide little in the way of comparison to the three different groups of districts of outperforming, at the norm (the majority), and underperforming. However, to date this modeling strategy has provided little in the way of helping to compare the model-identified outperforming districts to the "excellent" districts graded by the state accountability system. These comparisons are important, as the Bowers $(2010,2015)$ modeling framework is not intended to replace accountability systems, but rather to inform the study of districts throughout a state policy region. There is an interesting conversation to be had at the district and state level when these two systems agree or do not agree, and why.

\section{Framework of The Study}

The purpose of this study is to address the above issues and apply recent district effectiveness research (DER) site identification models across states, using hierarchical linear growth models in Ohio and Texas, including a broader set of time-varying demographic and financial covariates over an extensive period of time in both states. We identify groups of districts from the entire population of a state that are significantly outperforming peer districts. The goal is to further study outperformers as identified by the analyses in order to determine generalizable improvement approaches. For example, central office administrators from the outperforming districts could be brought together in collaboration with each state's department of education to provide professional development opportunities that focus on promoting state-level cross-district information sharing and improvement cycles. The reason we select these two states is to first replicate the previous results in Ohio with adding the additional finance variables noted above, and then second to apply to a very different state context, Texas, to examine the extent to which the modeling process will replicate to a very different state context, as far as geography, number of districts, school sizes, demographics, and achievement.

In the present study, our research questions are: 1) To what extent can outperforming or underperforming school districts in Ohio and Texas be identified by the model based on the long-term trends of multiple indicators? 2) To what extent is this identification system consistent with each state's current rating system? 3) To what extent do the district financial variables play 
a role in the growth trajectories of school districts for both Ohio and Texas?

\section{METHOD:}

\section{Sample:}

This study is a secondary data analysis of the publicly available data from the Ohio Department of Education (ODE) and Texas Education Agency (TEA). Specifically, we focused on administrative panel data for all school districts in Ohio $(n=608)$ during the academic years of 2005-2006 to 2011-2012 and for all districts in Texas $(n=1028)$ during the academic years of 20042005 to 2011-2012. Additionally, for both states, we merged the state data with publically accessible data from the National Center for Education Statistics (NCES) Common Core of Data (CCD) and the National Financial Survey to complement the state data with district financial, demographic and context variables.

\section{Variables:}

The dependent variable in the Ohio model is the district Performance Index (PI) Score, which captures the yearly performance of students across multiple grades for all tested subjects including mathematics, reading, social studies and science over a seven-year time span (2006- 2012). According to the calculation algorithm provided by ODE (2012) and Bowers (2010, 2015), the PI score is calculated as a weighted average of the percentages of student performance in advanced, basic and below basic categories for students in grades 3, 8 and 10 for all tested subjects, including reading, mathematics, science and social studies, with higher performance categories receiving higher weights after accounting for testing rates.

Because Texas did not report a single performance indicator for districts over this time period, the dependent variable in the Texas model is constructed from the publically available Texas Education Agency (TEA) dataset. The TEA dataset includes data on each district's scores on the standardized tests of Texas Assessment of Knowledge and Skills (TAKS), which measures students' abilities in reading, mathematics, science, social studies and writing across grades 3 to 11 for the years 2002-2012. After examining the missingness pattern of the whole dataset, we included in the final analysis the data from all non-charter public school districts in the state from 2004 to 2011 ( $n=1028)$. Lacking a single index measuring continuous performance and various aspects of school districts in Texas, we first calculated a PI score for each district in Texas following the Ohio PI score calculation metrics based on a recent report that summarizes similar PI metrics for all states in the U.S. (Ni, Bowers, \& Esswein, 2016).

\section{Independent Variables}

For the independent variables in both models, we followed previous literature on school and district effects (Bowers, 2010, 2015), which included Percentage of Disadvantaged Students, Percentage of Asian Students, Percentage of African American Students, Percentage of Hispanic Students and Percentage of Disabled Students. Percentage of High Mobility Students defined by ODE (2012) as the percentage of students who had attended schools in the district for two or less academic years. We then created three dichotomous variables to indicate urbanicity, (i.e., Urban, Small Town, and Rural, with Suburban as reference group) according to the local code variable listed by NCES CCD for each district (NCES, 2006). The variables Percentage of Student Attendance, Average Years of Teacher Experience, Student-Teacher Ratio, and Average Teacher Salary, and Schoollevel PI variance were included in the analysis as in the past studies (Condron \& Roscigno, 2003; Ferguson, 1991; Finn, Gerber, \& Boyd-Zaharias, 2005; Hanushek, 1989; Verstegen \& King, 1998). In addition, following the recommendations of previous research on categorizing district enrollment (Bowers \& Urick, 2011), we created the categories for enrollment of Small (1-1299), Large (2400-9999) and Extra Large (10,000 students and up), with medium enrollment as the reference group (13002399) in the Ohio model. However, in the Texas model, we categorized the enrollment data into five subgroups by adding an extra small category so as to better characterize the districts that have yearly enrollment less than 650 .

The model in the analysis extends the previous research (Bowers, 20102015 ) by examining the effects of the financial variables on the average Ohio and Texas district growth in PI score through the seven-year timespan. Following the previous literature (Card \& Payne, 2002; Okpala, Okpala, \& Smith, 2001; Payne \& Biddle, 1999), we included five financial variables in the current study from the National Public Education Financial Survey, which are Instruction expenditure per pupil, General Administration expenditure per pupil, School Administration per pupil, Instruction Staff Support Service expenditure per pupil and Capital Outlay - Construction expenditure per pupil. Table 1 and Table 2 summarize the descriptive statistics for the variables in the Ohio and Texas models.

\section{Analysis}

Our analysis strategy takes into account the recent critiques of Value Added Models (VAMs) (Hallinger, Heck, \& Murphy, 2014; Heck \& Hallinger, 2014) through using a hierarchical linear growth model to examine longitudinal district performance trends (Hox, 2010; Bowers \& White, 2014) in both Texas and Ohio, controlling for performance in the first year and then estimating the change over time as the slopes. We used SPSS 22 for all analyses. To correct for normality, we used a square root transformation for the ethnicity and financial variables. Also, we standardized all of the continuous variables into z-scores to grand mean center. Following the recommendations for specifying the covariance structure for repeated measures (Heck, et al., 2013), a diagonal error covariance matrix (DIAG) was specified at level 1 while an unstructured error covariance matrix (UN) was specified at level 2 . The full model analyzed in the analysis can be written as: 
Table 1: Descriptive of Ohio District Variables 2005-06 - 2011-12

\begin{tabular}{|c|c|c|c|c|}
\hline Variable & Mean & $(\mathrm{SD})$ & Min & $\operatorname{Max}$ \\
\hline Performance Index (PI) Score & 97.05 & $(6.27)$ & 69.80 & 112.40 \\
\hline$\%$ Disadvantaged students & 0.34 & $(0.02)$ & 0 & 1.00 \\
\hline$\%$ Asian students & 0.01 & $(0.016)$ & 0 & 0.17 \\
\hline$\%$ African American students & 0.06 & $(0.14)$ & 0 & 0.99 \\
\hline$\%$ Hispanic students & 0.02 & $(0.03)$ & 0 & 0.43 \\
\hline$\%$ High Mobility students & 0.39 & $(0.11)$ & 0.15 & 1 \\
\hline Small enrollment (vs. medium) & 0.35 & $(0.48)$ & 0 & 1.00 \\
\hline Large enrollment (vs. medium) & 0.30 & $(0.46)$ & 0 & 1.00 \\
\hline Extra Large enrollment (vs. medium) & 0.02 & $(0.15)$ & 0 & 1.00 \\
\hline Urban (vs. suburban) & 0.04 & $(0.18)$ & 0 & 1 \\
\hline Small Town (vs. suburban) & 0.12 & $(0.33)$ & 0 & 1 \\
\hline Rural (vs. suburban) & 0.47 & $(0.50)$ & 0 & 1.00 \\
\hline$\%$ Student attendance & 0.95 & $(0.016)$ & 0.89 & 0.98 \\
\hline School-level PI score variance & 4.11 & $(3.04)$ & 0.00 & 36.92 \\
\hline Avg. teacher years experience & 14.85 & $(3.27)$ & 4.00 & 34.00 \\
\hline Student - teacher ratio & 15.94 & $(1.97)$ & 0.87 & 49.73 \\
\hline Avg. teacher salary $(\$)$ & 51560.79 & $(7118.13)$ & 30,810 & 81851 \\
\hline Instruction expenditure per pupil (\$) & 5416.93 & $(897.75)$ & 3719.96 & 10808.95 \\
\hline $\begin{array}{l}\text { General Administration expenditure per } \\
\text { pupil (\$) }\end{array}$ & 264.22 & $(122.68)$ & 44.94 & 2635.61 \\
\hline $\begin{array}{l}\text { School Administration expenditure per } \\
\text { pupil (\$) }\end{array}$ & 540.12 & $(127.51)$ & 210.32 & 1495.32 \\
\hline $\begin{array}{l}\text { Instruction Staff Support Service } \\
\text { expenditure per pupil (\$) }\end{array}$ & 456.56 & $(236.90)$ & 11.71 & 1819.45 \\
\hline Capital Outlay expenditure per pupil (\$) & 1445.90 & $(3354.84)$ & 0 & 52896.96 \\
\hline $\mathrm{n}$ & 608 & & & \\
\hline Number of years of data & 7 & & & \\
\hline
\end{tabular}


Table 2: Descriptive of Texas District Variables 2004-05 - 2010-11

\begin{tabular}{|c|c|c|c|c|}
\hline Variable & Mean & $(\mathrm{SD})$ & Min & Max \\
\hline Performance Index (PI) Score & 92.95 & $(7.05)$ & 55.70 & 113.60 \\
\hline$\%$ Disadvantaged students & 0.54 & $(0.18)$ & 0 & 1.00 \\
\hline$\%$ Asian students & 0.09 & $(0.02)$ & 0 & 0.26 \\
\hline$\%$ African American students & 0.08 & $(0.12)$ & 0 & 0.86 \\
\hline$\%$ Hispanic students & 0.33 & $(0.27)$ & 0 & 1.00 \\
\hline Extra Small enrollment (vs. medium) & 0.39 & $(0.49)$ & 0 & 1.00 \\
\hline Small enrollment (vs. medium) & 0.20 & $(0.40)$ & 0 & 1.00 \\
\hline Large enrollment (vs. medium) & 0.19 & $(0.39)$ & 0 & 1.00 \\
\hline Extra Large enrollment (vs. medium) & 0.09 & $(0.29)$ & 0 & 1.00 \\
\hline Urban (vs. suburban) & 0.07 & $(0.25)$ & 0 & 1.00 \\
\hline Small Town (vs. suburban) & 0.15 & $(0.36)$ & 0 & 1.00 \\
\hline Rural (vs. suburban) & 0.60 & $(0.49)$ & 0 & 1.00 \\
\hline$\%$ Student attendance & 0.95 & $(0.01)$ & 0.92 & 0.99 \\
\hline School-level PI score variance & 6.06 & $(0.49)$ & 0.002 & 56.05 \\
\hline Avg. teacher years experience & 12.45 & $(2.38)$ & 0 & 29.50 \\
\hline Avg. teacher salary $(\$)$ & 41468.14 & $(4355.97)$ & 29209.16 & 74661.05 \\
\hline Student-Teacher ratio & 0.09 & $(0.02)$ & 0.03 & 0.30 \\
\hline Instruction expenditure per pupil (\$) & 40512.78 & $(201670.40)$ & 5.25 & 6015561.29 \\
\hline $\begin{array}{l}\text { General Administration expenditure per } \\
\text { pupil (\$) }\end{array}$ & 1081.85 & $(3061.45)$ & 0.71 & 79032.43 \\
\hline $\begin{array}{l}\text { School Administration expenditure per } \\
\text { pupil (\$) }\end{array}$ & 3802.93 & $(2222.80)$ & 0 & 687806.45 \\
\hline $\begin{array}{l}\text { Instruction Staff Support Service } \\
\text { expenditure per pupil (\$) }\end{array}$ & 3221.90 & (19278.99) & 0 & 623826.92 \\
\hline Capital Outlay expenditure per pupil (\$) & 13376.80 & $(65445.79)$ & 0 & 2065129.03 \\
\hline \multicolumn{5}{|c|}{1028} \\
\hline Number of years of data & 7 & & & \\
\hline
\end{tabular}


Level 1:

$P I_{t i}=\pi_{0 i}+\pi_{1 i}$ Year $_{t i}+e_{t i}$

Level 2:

$\pi_{0 i}=\beta_{00}+\beta_{01} X_{t i}+\cdots+u_{0 i}$

$\pi_{1 i}=\beta_{10}+\beta_{11} X_{t i}+\cdots+u_{1 i}$

in which:

$P I_{t i}=$ district PI score for district $i$ in time $t$

$X_{t i}=$ time - varying independent variables for each district $i$ in time $t$

Year $_{t i}=$ year $t$ of each district $i$

$\pi_{0 i}=$ intercepts varing randomly for each district $i$

$\pi_{1 i}=$ slopes varying randomly for each district $i$

$e_{0 i}=$ error in predicting PI for district $i$ in time $t$

$u_{0 i}=$ level 2 random components in predicting intercepts for district $i$

$u_{1 i}=$ level 2 random components in predicting slopes for district $i$

Finally, we created two sets of plots to visualize the results. First, following Bowers (2010, 2015), we plotted the model predicted gain versus the actual gain for both Ohio and Texas models. We calculated the model predicted PI scores for each district in the dataset by subtracting the first year PI score from the last year predicted PI score, and the same was done for actual PI score gain. The two gain score calculations were then plotted against each other to generate the final figure. Second, we created a quadrant plot for each state to compare the study findings to the state accountability ratings. The y-axis in the quadrant plot indicates the model predicted results, which we defined as PI Gain Index. We calculated PI Gain Index by subtracting the model predicted gain from the actual PI score gain. The $\mathrm{X}$-axis is the school letter rating as defined by each state. In the Ohio model, the $\mathrm{x}$-axis is the percentage of the standards met, scaling from 0 to 100; in the Texas model, the $\mathrm{x}$-axis is the 4-year High School Completion Rate.

\section{RESULTS:}

In this section, we first present the overall PI score trajectories for all districts in both Ohio and Texas to provide a visualization of the change-over-time for all districts in each state. Second, we present the fit of the model to the data in both Ohio and Texas, and examine the extent to which different context, demographic and financial variables affect the model. Third, we present the comparison of predicted PI score gains versus actual PI score gains and discuss the "outperforming" districts identified by the models in both states. Finally, we visualize the outperforming districts identified from the model compared to the "excellent" districts graded by the state accountability system to provide further considerations for state evaluation systems in both states.

\section{Examining Ohio and Texas school district PI score trajectories}

Figure 1.1 plots the seven-year longitudinal trajectories in PI score for each of the 608 districts in Ohio, from academic year of 2005-2006 to 2011-12, as each line represents one district. Figure 1.2 plots the seven-year trajectories in PI score for each of the 1028 districts in Texas. The range of Performance Index score Bowers, Ni, \& Esswein (2018) was from 0 to 120 , however, there were no districts with a PI score under 50. Overall for each state, Figures 1.1 and 1.2 show that while there is a slight increasing trajectory over the seven years, and there are a few districts at the lower end of the scale with more variance year-over-year, in general the vast majority of school districts perform similar to the previous year and mirror the overall slight trajectory increase for the entire state.

\section{Figure 1.1 Seven-Year Trends in 608 Ohio District PI Scores}

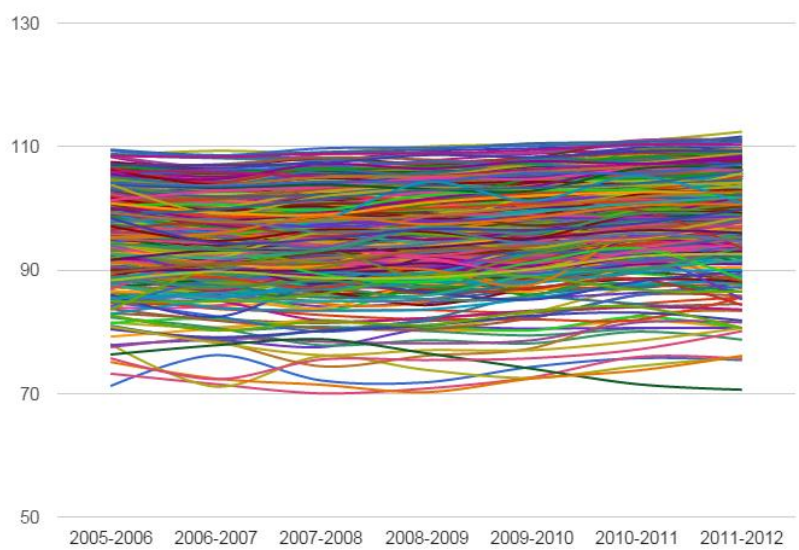

Academic Year

Figure 1.1: Seven years of PI scores for all districts in Ohio. Seven years of consecutive PI score data for the full population of school districts in the state of Ohio are plotted. Each line represents the trend of one of the 608 individual district seven-year history of PI score change. Districts trends are plotted from 50-120, since no districts scored below 50 PI score at any time.

\section{Figure 1.2 Seven-Year Trends in 1028 Texas District PI Scores}

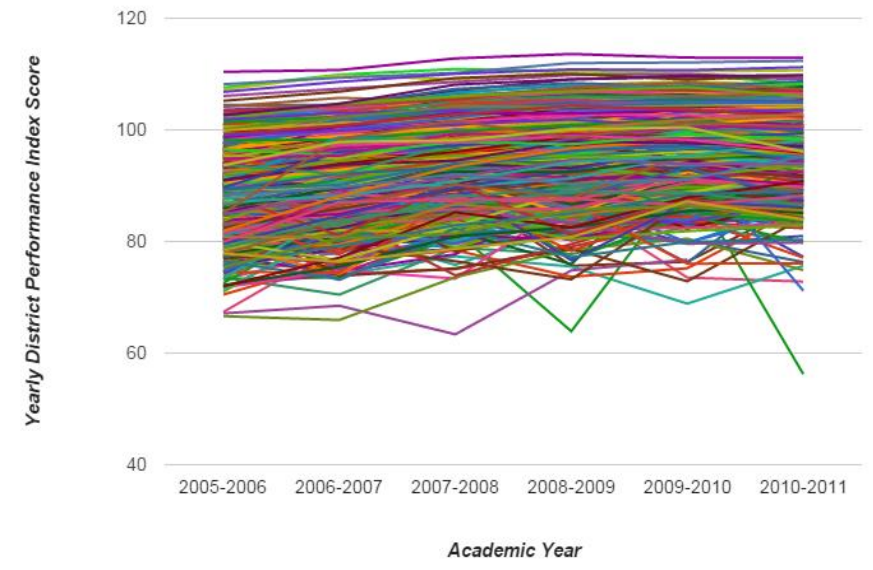

Figure 1.2: Seven years of PI scores for all districts in Texas. Seven years of consecutive PI score data for the full population of school districts in the state of Texas are plotted. Each line represents the trend of one of the 1028 individual 
district seven-year history of PI score change. Districts trends are plotted from 40-120, since no districts scored below 40 PI score at any time.

\section{Hierarchical linear growth model of Ohio and Texas PI change}

The unconditional null hierarchical linear growth model with time included for Ohio had a high interclass correlation coefficient (ICC) of $73.16 \%$, indicating that over half of the variance in PI score is between districts. This high between district variance indicates that the growth over time within districts was fairly low, with more variance between districts. This mirrors Figure 1.1 in which one can see the variance up and down the scale between districts, with only slight changes within districts over time (left to right). Table 3 provides the results for the full seven-year hierarchical linear growth model. All variables are rescaled (zscored or categorized) such that all coefficients can be interpreted for the "average" district, a district that would be at the averages for all continuous variables and the reference groups for the categorical variables (medium enrollment and suburban). The unconditional null hierarchical growth model with time included for Texas has an ICC of $50.49 \%$, indicating more than half the variance in PI score can be explained between districts. This is evidenced in Figure 1.2 as there is much more variance in change over time as many districts rise over time while others show more of a "sawtooth" effect over time, especially for the lower performing districts. Table 3 provides the results for the full seven-year hierarchical linear growth model. All variables are zscored or categorized so that all coefficients for all continuous variables can be interpreted as the average effect for all the 1028 districts.

Parameter estimates for each model replicate and extend the previous studies in Ohio (Bowers, 2010, 2015). Hierarchical linear growth models have two components, the intercept part of the model which controls for prior achievement and context effects, which is analogous to a single cross-sectional regression for the first year of data included in the model, and then the slope component of the model, which examines the effect of each variable on the growth over time in PI score for each state. For both Ohio and Texas, the demographic and context variables generally mirror the previous studies, both in effect size and significance in both the intercept and slope components of the model. This demonstrates that the modeling framework generalizes well from Ohio to the Texas context.

Next, following the recommendations from the previous Ohio studies (Bowers, 2010, 2015), we subtracted the 2012 Actual PI score for each district from the 2006 actual PI score, and did the same for the predicted scores, and then plotted them in Figure 2.1 for the 608 districts with complete data across all seven years to examine the distribution of performance in Ohio. Figure 2.1 provides a means to examine which districts significantly outperform or underperform based on their demographic and context variables. Here, districts separate into three groups, with fifteen districts lying above the 95\% confidence interval. We conducted the same procedure with the Texas dataset and identified 32 districts lying above the $95 \%$ confidence interval, as shown in Figure 2.2. Each dot represents a district, and districts are labeled by their state AYP accountability rating for the final year of the model. As the model controls for context, demographics, and finance variables, we argue that these districts should be considered for more in-depth analysis, especially qualitative case studies, as our results would suggest that these districts outperform other similar districts and perhaps may be considered effective, equitable and efficient as they outperform other similar districts in the state when controlling for these three types of variables.

Finally, we created a quadrant plot comparing the findings of this study to the state accountability ratings for both Ohio and Texas, which are displayed in Figure 3.1 and Figure 3.2 separately. In Figures 3.1 and 3.2 , the $y$-axis indicates the model predicted results, which we defined as PI Gain Index. This was calculated by subtracting the model predicted gain from the actual sevenyear PI score gain. The mean of the PI gain index is -0.47 for Ohio and -0.43 for Texas, indicating the average actual 7-year gain is slightly larger than the model predicted 7-year PI gain for both states. The $\mathrm{x}$-axis is the percentage of standards met adopted by Ohio in Figure 3.1 while it is the 4-year high school completion rates for Texas in Figure 3.2, which are the main indications of Annual Yearly Progress (AYP) for both states. The vertical dashed line is the average percentage of the standards met for the districts across the state and the two horizontal dashed lines are the $95 \%$ confidence interval boundary of the PI Gain Index. We also set the markers by the district letter grade for 2010-2011 rated by the Ohio Department of Education (ODE) in Figure 3.1 and district rating grade for 2011-2012 by the Texas Education Agency (TEA). Thus, the three dashed lines separate the districts outside the 95\% confidence interval of PI Gain Index into four groups, where we defined the upper left as low-high; upper right as high -high; lower left as low-low and lower right as high-low. Districts in the high-high quadrant (top right) outperform the model here and are rated highly by their state, and thus the two modeling frameworks agree. For the low-low (bottom left) the same can be said as the models agree. However, for the districts in the low-high quadrant (upper left) the model suggests that they should be outperforming, yet by the state accountability indicator they are seen as having less than average performance. The districts in the middle of the plot but above the state averages on the $\mathrm{x}$-axis (far right, middle) are also an interesting group as the model would say that these districts are at the norm when controlling for their contexts and demographics, yet the state rates them very highly. This is mostly likely due to the model controlling for variables such as poverty.

We argue here that the quadrant plots provide a new means for practitioners, researchers and policy makers to identify outperforming or underperforming long-term district performance trends in their states, and surface interesting differences between the state AYP accountability rating system and a more controlled modeling framework such as the hierarchical linear growth model. Note that our argument here is not to replace the state accountability systems; instead, this set of models and visualization is meant to invite further investigation, and help districts bring together central office personnel for professional development, in which district contexts can be matched across 
Table 3: Parameter estimates for a hierarchical linear growth model of Ohio and Texas PI score change 200405 - 2010-11

\begin{tabular}{|c|c|c|c|c|c|c|}
\hline \multirow[b]{2}{*}{ Variable } & \multicolumn{3}{|c|}{$\begin{array}{l}\text { Ohio PI score change 2005- } \\
06-2011-12\end{array}$} & \multicolumn{3}{|c|}{$\begin{array}{l}\text { Texas PI score change } 2004-05 \\
-2010-11\end{array}$} \\
\hline & Coeff. & $(S E)$ & $\begin{array}{l}\text { Stand. } \\
\text { coeff. }\end{array}$ & Coeff. & $(S E)$ & $\begin{array}{l}\text { Stand. } \\
\text { coeff. }\end{array}$ \\
\hline Intercept & $96.101 * * *$ & $(0.307)$ & - & $89.684 * * *$ & $(0.444)$ & - \\
\hline Year & $0.511 * * *$ & $(0.049)$ & 0.081 & $1.445 * * *$ & $(0.083)$ & 0.205 \\
\hline \multicolumn{7}{|l|}{ Intercepts } \\
\hline \%Disadvantage students & $-1.248 * * *$ & $(0.109)$ & -0.199 & $-2.182 * * *$ & $(0.170)$ & -0.310 \\
\hline$\%$ Asian students ${ }^{\mathrm{a}}$ & $0.689 * * *$ & $(0.138)$ & 0.110 & $0.590 * * *$ & $(0.142)$ & 0.083 \\
\hline$\%$ African American students ${ }^{\mathrm{a}}$ & $-1.401 * * *$ & $(0.137)$ & -0.223 & $-1.298 * * *$ & $(0.151)$ & -0.184 \\
\hline$\%$ Hispanic students $^{\mathrm{a}}$ & $0.266^{*}$ & $(0.170)$ & 0.042 & $-2.034 * * *$ & $(0.192)$ & -0.288 \\
\hline \% High mobility students & -0.095 & $(0.067)$ & & $-0.558 * * *$ & $(0.097)$ & -0.079 \\
\hline$\%$ Disabled students & $-0.601 * * *$ & $(0.098)$ & -0.096 & $-0.420 * * *$ & $(0.102)$ & -0.060 \\
\hline Extra-small enrollment & - & - & - & $-1.104 * * *$ & $(0.390)$ & -0.077 \\
\hline Small enrollment & -0.181 & $(0.262)$ & & -0.1192 & $(0.297)$ & \\
\hline Large enrollment & $0.521^{*}$ & $(0.261)$ & 0.038 & -0.134 & $(0.386)$ & \\
\hline Extra-large enrollment & 0.087 & $(0.775)$ & & -0.427 & $(0.603)$ & \\
\hline Urban & $-6.499 * * *$ & $(0.928)$ & -0.186 & 0.580 & $(0.636)$ & \\
\hline Small Town & $-2.178 * * *$ & $(0.537)$ & -0.115 & $1.272 * * *$ & $(0.500)$ & 0.064 \\
\hline Rural & $-1.517 * * *$ & $(0.398)$ & -0.120 & $0.951 *$ & $(0.457)$ & 0.066 \\
\hline$\%$ Student attendance & $0.740 * * *$ & $(0.087)$ & 0.118 & $0.469 * * *$ & $(0.103)$ & 0.067 \\
\hline School-level PI score variance & -0.044 & $(0.052)$ & & $-0.249 * * *$ & $(0.161)$ & -0.036 \\
\hline Avg. teacher years experience & $0.417 * * *$ & $(0.078)$ & 0.067 & $0.259 * * *$ & $(0.114)$ & 0.036 \\
\hline Student-teacher ratio & $-0.227 *$ & $(0.089)$ & -0.036 & $1.250 * * *$ & $(0.216)$ & 0.177 \\
\hline Avg. teacher salary & -0.169 & $(0.131)$ & & $2.189 * * *$ & $(0.121)$ & 0.310 \\
\hline $\begin{array}{l}\text { Instruction expenditure per } \\
\text { pupil }^{\text {a }}\end{array}$ & 0.175 & $(0.142)$ & & -0.821 & $(0.833)$ & \\
\hline $\begin{array}{l}\text { General Administration } \\
\text { expenditure per pupil }{ }^{\mathrm{a}}\end{array}$ & $-0.267 * * *$ & $(0.088)$ & -0.043 & $-0.693 * * *$ & $(0.252)$ & -0.098 \\
\hline $\begin{array}{l}\text { School Administration } \\
\text { expenditure per pupil }\end{array}$ & -0.033 & $(0.092)$ & & $0.379 * * *$ & $(0.173)$ & 0.054 \\
\hline $\begin{array}{l}\text { Instruction Staff Support } \\
\text { Service expenditure per pupil }\end{array}$ & 0.131 & $(0.106)$ & & 0.827 & $(0.759)$ & \\
\hline $\begin{array}{l}\text { Capital Outlay expenditure per } \\
\text { pupil }^{\text {a }}\end{array}$ & -0.111 & $(0.062)$ & & -0.057 & $(0.171)$ & \\
\hline \multicolumn{7}{|l|}{ Slopes } \\
\hline \%Disadvantage & $0.281 * * *$ & $(0.028)$ & 0.140 & 0.029 & $(0.033)$ & \\
\hline$\%$ Asian & $-0.067 *$ & $(0.030)$ & -0.034 & -0.012 & $(0.029)$ & \\
\hline$\%$ African American & $-0.193 * * *$ & $(0.029)$ & -0.097 & $0.146^{* * *} *$ & $(0.027)$ & 0.073 \\
\hline$\%$ Hispanic & -0.009 & $(0.021)$ & & $0.160 * * *$ & $(0.034)$ & 0.080 \\
\hline$\%$ Mobile rate & -0.003 & $(0.017)$ & & $0.052 *$ & $(0.025)$ & 0.026 \\
\hline
\end{tabular}




\begin{tabular}{|c|c|c|c|c|c|c|}
\hline \%Disabled students & $-0.046^{*}$ & $(0.022)$ & -0.023 & 0.050 & $(0.026)$ & \\
\hline Extra-small enrollment & - & - & - & -0.040 & $(0.085)$ & \\
\hline Small enrollment & 0.056 & $(0.050)$ & & -0.020 & $(0.066)$ & \\
\hline Large enrollment & -0.037 & $(0.055)$ & & 0.052 & $(0.073)$ & \\
\hline Extra-large enrollment & -0.050 & $(0.148)$ & & 0.213 & $(0.114)$ & \\
\hline Urban & -0.047 & $(0.121)$ & & -0.196 & $(0.101)$ & \\
\hline Small town & 0.015 & $(0.070)$ & & $-0.287 * * *$ & $(0.079)$ & -0.052 \\
\hline Rural & $0.112 *$ & $(0.051)$ & 0.028 & $-0.160 *$ & $(0.073)$ & -0.040 \\
\hline$\%$ Student attendance & -0.024 & $(0.021)$ & & 0.025 & $(0.024)$ & \\
\hline School-level PI score variance & $-0.053 * * *$ & $(0.016)$ & -0.027 & 0.006 & $(0.016)$ & \\
\hline Avg. teacher experience & $-0.087 * * *$ & $(0.018)$ & -0.044 & -0.019 & $(0.025)$ & \\
\hline Student -teacher ratio & 0.029 & $(0.020)$ & & $-0.134 * *$ & $(0.050)$ & -0.067 \\
\hline Avg. teacher salary & $0.186^{* * *}$ & $(0.031)$ & 0.093 & $-0.377 * * *$ & $(0.026)$ & -0.189 \\
\hline $\begin{array}{l}\text { Instruction expenditure per } \\
\text { pupil }^{\text {a }}\end{array}$ & $0.081 *$ & $(0.033)$ & 0.041 & $-0.391 *$ & $(0.173)$ & -0.199 \\
\hline $\begin{array}{l}\text { General Administration } \\
\text { expenditure per pupil }{ }^{\mathrm{a}}\end{array}$ & 0.040 & $(0.022)$ & & -0.026 & $(0.055)$ & \\
\hline $\begin{array}{l}\text { School Administration } \\
\text { expenditure per pupil }\end{array}$ & -0.005 & $(0.020)$ & & -0.035 & $(0.039)$ & \\
\hline $\begin{array}{l}\text { Instruction Staff Support } \\
\text { Service expenditure }^{\mathrm{a}}\end{array}$ & 0.008 & $(0.021)$ & & $0.326^{*}$ & $(0.159)$ & 0.0163 \\
\hline $\begin{array}{l}\text { Capital Outlay expenditure per } \\
\text { pupil }^{\mathrm{a}}\end{array}$ & 0.012 & $(0.016)$ & & 0.049 & $(0.043)$ & \\
\hline $\begin{array}{l}\text { Amount of Variance between } \\
\text { districts (ICC) }(\%) \\
\text { Variance Explained }\end{array}$ & 73.16 & & & 50.49 & & \\
\hline Level1: within districts (\%) & 16.07 & & & 12.940 & & \\
\hline Level2: between districts $(\%)$ & 68.87 & & & 60.039 & & \\
\hline
\end{tabular}

Notes:

a: \% Asian, African American, Hispanic student, Instruction expenditure per pupil, General Administration expenditure per pupil, School Administration expenditure per pupil, Instruction Staff Support Service expenditure per pupil, Capital Outlay expenditure per pupil are square root transformed.

All variables are standardized (z-score) except for the enrollment and locale dichotomous variables. 


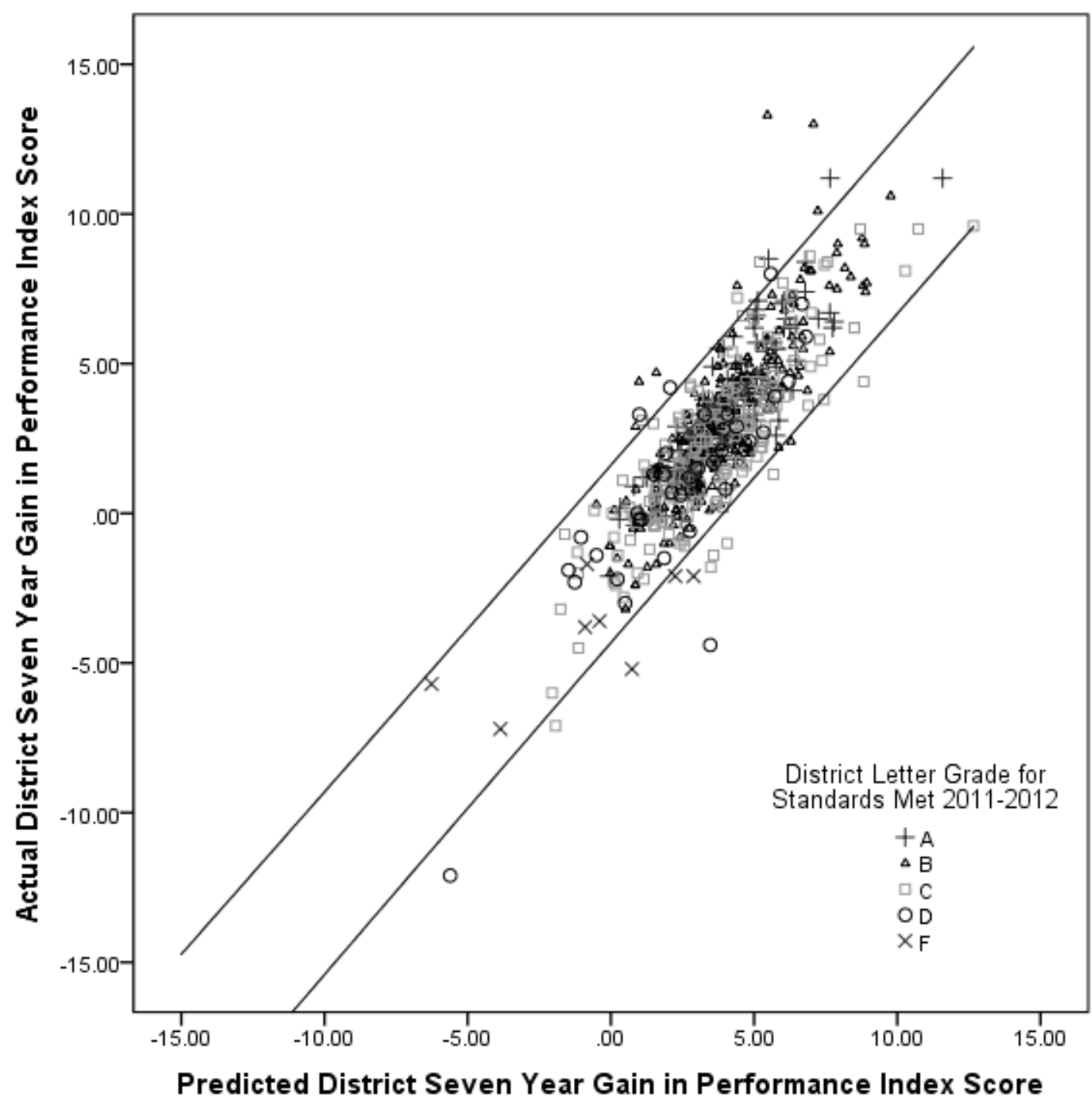

Figure 2.1: Comparison of predicted versus actual seven-year Performance Index (PI) score gain in Ohio, 2005-06 - 2011-12. Hierarchical linear growth modeling predicted PI score gains are plotted on the x-axis for each of the 608 districts in Ohio over the time period, versus the actual gains from 2005-06 to 2011-12. The 95\% confidence intervals are shown. Individual districts are plotted as symbols representing the Ohio Department of Education for district accountability rating, with A being the best as Exemplary Performance and $\mathrm{F}$ as Academically Unacceptable. Districts that are outside 95\% confidence interval are designated as significantly outperforming or underperforming their demographic and context variables. 


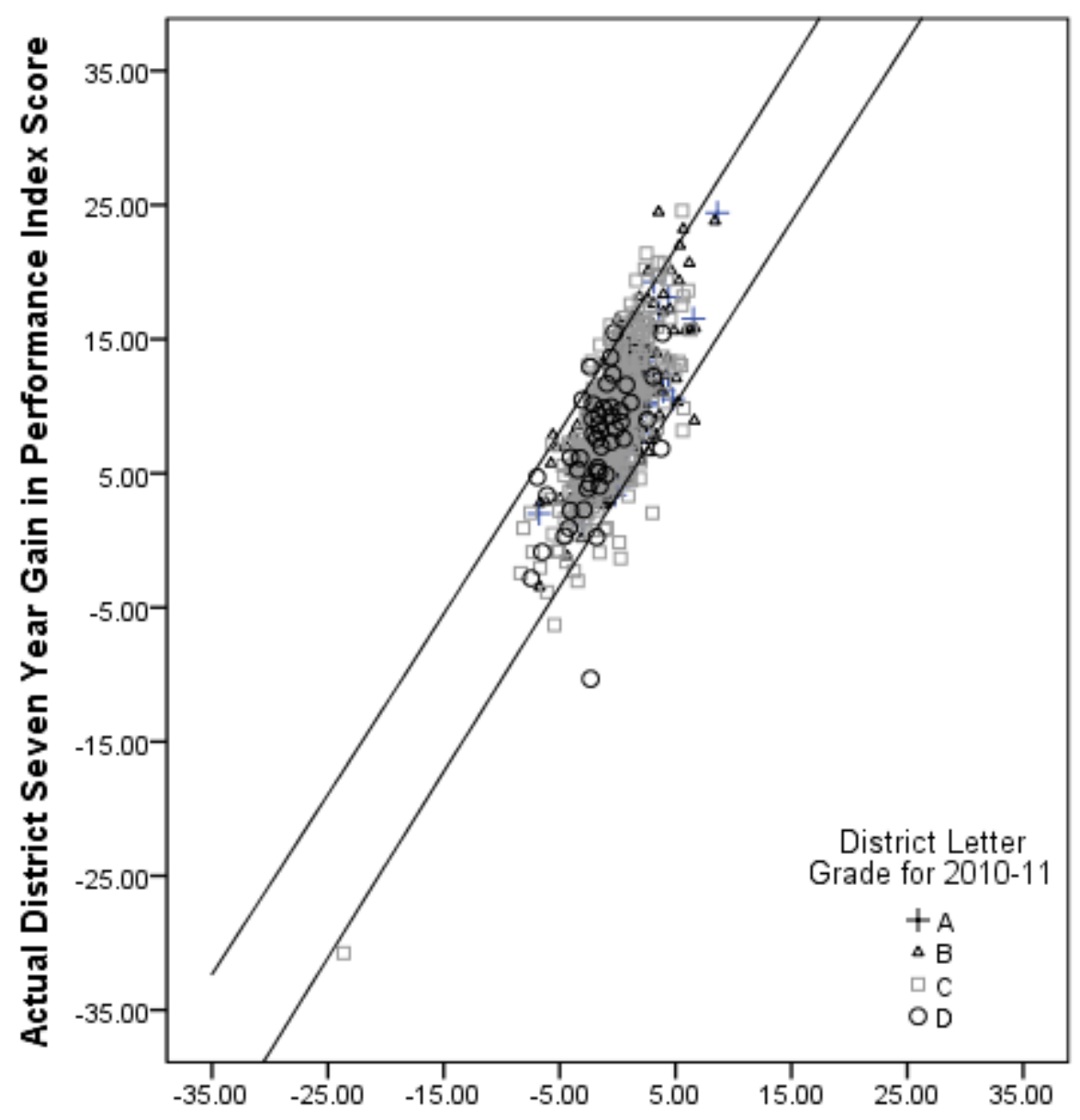

PIS_Gain_Index_Actual_Minus_Predict

Figure 2.2: Comparison of predicted versus actual seven-year Performance Index (PI) score gain in Texas Hierarchical linear growth modeling predicted PI score gains are plotted on the $\mathrm{x}$-axis for each of the 1028 districts in Texas over the time period, versus the actual gains from 2004-05 to 2012-13. The 95\% confidence intervals are shown. Individual districts are plotted as symbols representing the Texas Department of Education for district accountability rating, with A being the best as Exemplary Performance and D as Academically Unacceptable. Districts that are outside $95 \%$ confidence interval are designated as significantly outperforming or underperforming their demographic and context variables. 
HLM growth models (low in one high in the other, or low in both), as the HLM approach takes advantage of long-term growth while most of the state systems use single year performance for AYP status.

\section{CONCLUSION:}

This study demonstrates the utility of using a systems-level analysis of organizations across entire states to understand which school districts in a U.S. state are outperforming similar districts when controlling for multiple variables that are outside the control of the district administration, including context and background variables. Here, we have shown that within the District Effectiveness Research (DER) framework, the hierarchical linear growth modeling strategy controlling for context, demographics and finance variables can work well to identify a set of districts that may be "unusually effective", demonstrating the model in two very different states, Ohio and Texas. As noted in the previous literature in this domain (Bowers, 2008, 2010, 2015), these "outperforming" districts then must be studied using in-depth qualitative studies to understand how the districts outperform other districts in their state that are in similar community contexts. Additionally, comparisons made between state-determined ratings and HLM results has the potential for better understanding of state methods for identifying under and outperforming districts.

\section{Understanding and improving state accountability systems}

The purpose of the analyses presented in this chapter, namely using HLM in this way to identify outperforming districts, is different from that of state-determined ratings. Due to the fact that states not only have the common purpose of identifying schools in need of supplemental support as defined by federal law, they also need to consider a wide range of stakeholders as well as political context. It is for this reason that we do not expect that districts identified as outperforming by the HLM would necessarily be similar to state ratings. Furthermore, because the HLM tracks progress over time, it is possible that districts with high populations of historically underperforming students that are identified as overachieving by the HLM have improved as a result of the additional, targeted support from states. In some cases, it is possible the support was not enough to improve the state's calculation for the district, but enough to grow their population over time. Figures such as 3.1 and 3.2, however, can provide valuable insight to state departments of education as they implement and refine their accountability and school improvement systems under ESSA such as examining what are the common characteristics across districts within each quadrant of figures such as 3.1 and 3.2? This leads to understanding why a district would be considered outperforming by the HLM, but poorly rated by the state's system, for example. Investigations such as this can help the state calculations identify schools and districts that better reflect initial intentions of the system. Changes to state calculations could include creating conditions that honor growth revealed by the HLM, or excluding indicators unintentionally causing disagreement of the two methods.

\section{District collaboration and further qualitative study}

Despite the abundance of information drawn from the many variables considered in theses analyses, this type of modeling falls short of providing reasons for which some districts excel despite consisting of historically underperforming populations of students while others continue to fall farther behind. The final plots presented in Figures 2.1-2.2 and 3.1-3.2 demonstrate a possible next step in this framework for district effectiveness research. For the 15 districts identified as outperforming in Ohio and the 32 districts in Texas, we propose here that the next step in helping districts across a state improve is to gather outperforming districts to begin to identify possible generalizable improvement approaches for further investigation and qualitative deep-dives.

One approach to further investigation is to convene central office staff of the outperforming districts to attend a multi-day work session either through a district or state-led approach. During the convening, attendees could be provided interactive discussion events in which the discussion is guided to surface initial ideas on how each district finds success in its context, and what is idiosyncratic to that context, and what may be generalizable. This type of conversation can mirror similar types of data and evidence-based conversations and protocols currently being used to help teachers in schools develop improvement strategies around the evidence and processes in their schools (Bowers, 2017). This type of gathering can serve three very important roles. First, central office leaders can build a network of colleagues across the state who are doing similar work, and finding similar success. Second, understanding what may be idiosyncratic to the local context is important, as this type of finding can be very helpful to other districts that may not be as successful, but may have experienced similar challenges in a similar or related context. Third, gathering the collective learning from across the top outperforming districts can not only help the other districts across the state know what the similar processes are that are shared across these districts that may lead to increased performance, but the state department of education and the legislature can gain a valuable set of allies in helping in statelevel instructional improvement and policy. These districts are most likely have figured out how to best leverage the policies for helping their students, as previous research has noted (Bowers, 2008; Thompson, Sykes, \& Skrla, 2008; Skrla, McKenzie, Scheurich, \& Dickerson, 2011).

For further study, districts at or below the norm could pair with outperforming districts with similar student populations to understand processes and foci in order to learn what is transferrable. State departments may not always have resources to facilitate this, and therefore district collaboration does not necessarily need to be led at the state level. For example, districts may develop programs to share their successes with other districts in the state in which other districts may send staff to visit selected classrooms and hold in-depth conversations with school leadership. Overall though, after such a workshops (either at individual districts or larger gatherings across districts with state administration) and reporting the results to the state, we encourage states to consider pairing districts at the norm with one of the outperforming districts, to have the central office staffs and 


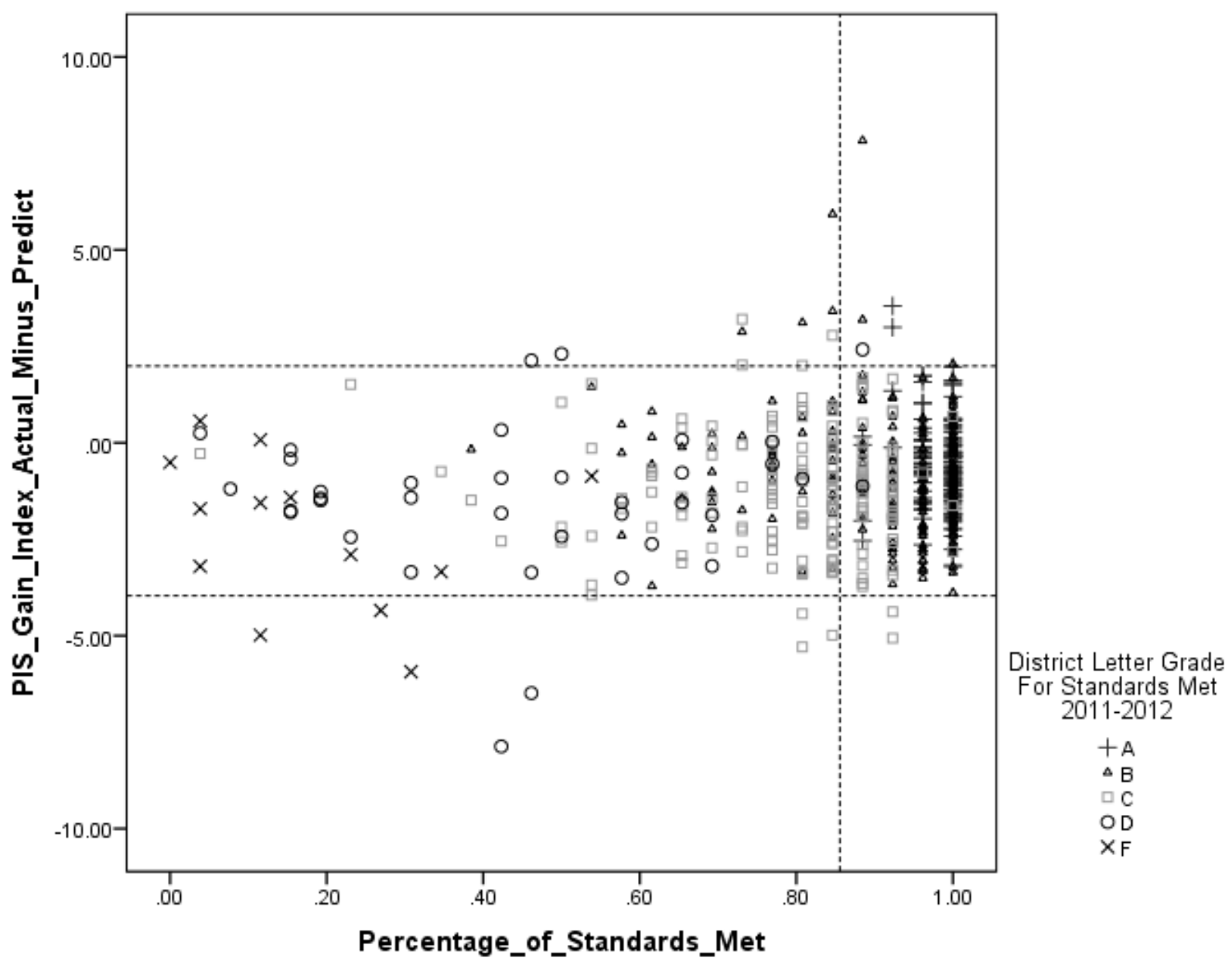

Figure 3.1: Quadrant Plot for model results versus Ohio accountability ratings.

The difference between hierarchical linear growth modeling predicted PI score gains and actual gain are plotted on the y-axis for each of the 608 districts in Ohio over the time period, versus the percentage of standards met on the x-axis. The $95 \%$ confidence intervals are shown as dotted lines. Individual districts are plotted as symbols representing the Ohio Department of Education district accountability rating, with A being the best as Exemplary Performance and $\mathrm{F}$ as Academically Unacceptable. 


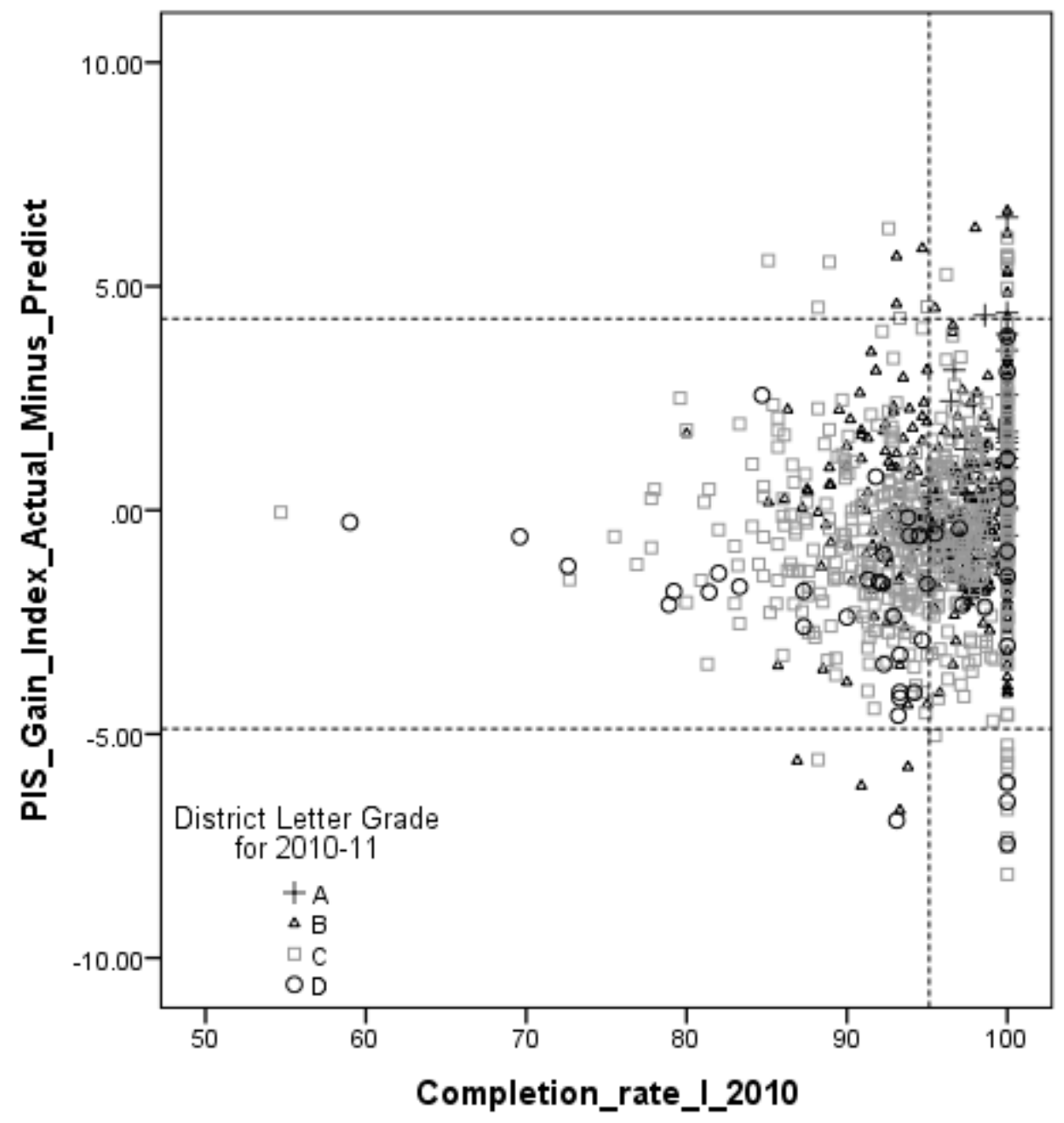

Figure 3.2: Quadrant Plot for model results versus Texas accountability ratings.

The difference between hierarchical linear growth modeling predicted PI score gains and actual gain are plotted on the y-axis for each of the 1028 districts in Texas over the time period, versus the 4-year high-school completion rates for 2010-2011 on the x-axis. The $95 \%$ confidence intervals are shown as dotted lines. Individual districts are plotted as symbols representing the Texas Department of Education for district accountability rating, with A being the best as Exemplary Performance and F as Academically Unacceptable. 
principals meet periodically over multiple years, tour each other's campuses, and discuss how their operations and instructional focus may differ, and how they may be able to collaborate. There may be much to learn from each of the district locations, and district central office administrators rarely have an opportunity to engage over a long period of time in discussing these types of differences and possible improvement activities and professional development. In this way, districts across the system may inform their learning and practices through these types of systematic evidence-informed collaborative opportunities.

\section{Limitations}

While we argue that our results are robust, this study is limited in multiple ways. First, while we included two states with different contexts and seven years of data for each state, this study thus does not consider the extent to which this modeling framework may perform in the other 48 states in the US, or across nations. Second, while the longitudinal data included seven years of data, the final years of the models were 2011-2012 (Ohio) and 2010-11 (Texas). These end dates were selected as for each state the testing regime changed, as the states transitioned to new assessment procedures and new standardized tests across subjects, making it difficult to study longitudinal performance beyond these dates. This necessarily focuses the models on the first decade of the $21^{\text {st }}$ century. We encourage future research to consider more recent data that includes all of the years since, as well as to consider how to adapt the models to perhaps account for the test changes over time. Third, our definition of effectiveness of calculating the Performance Index Score, while an improvement over previous district effectiveness research that focused on just cross-sectional English or mathematics test scores, still consists of state standardized assessments, even if these include many grade levels and subjects over time. We encourage future research to examine district effectiveness through broader conceptions of "effective" beyond test scores, including student socio-emotional learning and grades, student graduation from high school, college admission, college degree completion, citizenship, community engagement and volunteerism, and career training, readiness, and placement. Examining the difference in which districts outperform on these broader measures of effectiveness across a state could provide valuable insights into how to successfully serve students and communities across a broad range of potential positive schooling outcomes.

\section{Suggested Citation:}

Bowers, A.J., Ni, X., Esswein, J. (2018) Using Hierarchical Growth Modeling to Promote District Systematic Improvement in Ohio and Texas. In Shaked, H., Schechter, C., Daly, A. (Eds.) Leading Holistically: How Schools, Districts, and States Improve Systemically (p.77-100). Routledge.

https://www.taylorfrancis.com/books/e/9781351362191/chapters/ 10.4324\%2F9780203712184-5

\section{REFERENCES:}

Bowers, A. J. (2008). Promoting Excellence. Leadership and Policy in Schools, 7(2), 154-177.

Bowers, Ni, \& Esswein (2018)
Bowers, A. J. (2010). Toward Addressing the Issues of Site Selection in District Effectiveness Research: A Two-Level Hierarchical Linear Growth Model. Educational Administration Quarterly, 46(3), 395-425. https://doi.org/10.1177/0013161X10375271

Bowers, A. J. (2015). Site selection in school district research: a measure of effectiveness using hierarchical longitudinal growth models of performance. School Leadership \& Management, 35(1), 39-61. https://doi.org/10.1080/13632434.2014.962500

Bowers, A.J. (2017) Quantitative Research Methods Training in Education Leadership and Administration Preparation Programs as Disciplined Inquiry for Building School Improvement Capacity. Journal of Research on Leadership Education, 12(1), p.72-96. http://doi.org/10.1177/1942775116659462

Bowers, A. J., \& Lee, J. (2013). Carried or defeated? Examining the factors associated with passing school district bond elections in Texas, 1997-2009. Educational Administration Quarterly, $0013161 X 13486278$.

Bowers, A. J., \& Urick, A. (2011). Does high school facility quality affect student achievement?: A two-level hierarchical linear model. Journal of Education Finance, 37(1), 72-94.

Bowers, A. J., and B. R. White. 2014. "Do Principal Preparation and Teacher Qualifications Influence Different Types of School Growth Trajectories in Illinois? A Growth Mixture Model Analysis." Journal of Educational Administration 52 (5): 705 736. doi:10.1108/JEA-12-2012-0134.

Bryk, A. S. (2010). Organizing schools for improvement. Phi Delta Kappan, 91(7), 23.

Bryk, A. S., Gomez, L. M., \& Grunow, A. (2011). Getting ideas into action: Building networked improvement communities in education. In Frontiers in sociology of education (pp. 127-162). Springer. Retrieved from http://link.springer.com/10.1007\%2F978-94-007-1576-9_7

Card, D., \& Payne, A. A. (2002). School finance reform, the distribution of school spending, and the distribution of student test scores. Journal of Public Economics, 83(1), 49-82.

Chingos, M. M., Whitehurst, G. J., \& Gallaher, M. R. (2015). School Districts and Student Achievement. Education Finance and Policy, 10(3), 378-398.

https://doi.org/10.1162/EDFP_a_00167

Condron, D. J., \& Roscigno, V. J. (2003). Disparities within: Unequal Spending and Achievement in an Urban School District. Sociology of Education, 76(1), 18-36. https://doi.org/10.2307/3090259 
Daly, A. J., \& Finnigan, K. S. (2012). Exploring the space between: Social networks, trust, and urban school district leaders. Journal of School Leadership, 22(3), 493-530.

Daly, A. J., \& Finnigan, K. S. (Eds.). (2016). Thinking and Acting Systemically: Improving School Districts Under Pressure (Reprint edition). Washington, DC: Amer Educational Research Assn.

Elmore, R. F., \& Burney, D. (1997). Investing in Teacher Learning: Staff Development and Instructional Improvement in Community School District\# 2, New York City. ERIC. Retrieved from http://eric.ed.gov/?id=ED416203

Ferguson, R. F. (1991). Racial Patterns in How School and Teacher Quality Affect Achievement and Earnings. Challenge, 2(1), 1-35.

Finn, J. D., Gerber, S. B., \& Boyd-Zaharias, J. (2005). Small Classes in the Early Grades, Academic Achievement, and Graduating From High School. Journal of Educational Psychology, 97(2), 214-223. https://doi.org/10.1037/00220663.97.2.214

Hanushek, E. A. (1989). The Impact of Differential Expenditures on School Performance. Educational Researcher, 18(4), 45-62. https://doi.org/10.3102/0013189X018004045

Honig, M. I. (2003). Building Policy from Practice: District Central Office Administrators' Roles and Capacity for Implementing Collaborative Education Policy. Educational Administration Quarterly, 39(3), 292-338. https://doi.org/10.1177/0013161X03253414

Honig, M. I. (2008). District central offices as learning organizations: How sociocultural and organizational learning theories elaborate district central office administrators' participation in teaching and learning improvement efforts. American Journal of Education, 114(4), 627-664.

Honig, M. I., \& Rainey, L. R. (2015). How School Districts Can Support Deeper Learning: The Need for Performance Alignment. Deeper Learning Research Series. Jobs for the Future. Retrieved from http://eric.ed.gov/?id=ED560756

Hox, J. 2010. Multilevel Analysis: Techniques and Applications. 2nd ed. New York: Routledge.

Leithwood, K. (2010). Characteristics of School Districts that Are Exceptionally Effective in Closing the Achievement Gap.

Leadership and Policy in Schools, 9(3), 245-291.

https://doi.org/10.1080/15700761003731500

Ni, X., Bowers, A.J., Esswein, J. (2016) What Counts in Calculating School and District Level Performance Index Scores: A Summary and Analysis of Academic Performance Index Metrics across the 50 States. Teachers College, Columbia University. http://dx.doi.org/10.7916/D86973RR
O'Connor, J., \& McDermott, I. (1997). The art of systems thinking: Essential skills for creativity and problem solving. San Francisco, CA: Thorsons.

Okpala, C. O., Okpala, A. O., \& Smith, F. E. (2001). Parental Involvement, Instructional Expenditures, Family Socioeconomic Attributes, and Student Achievement. The Journal of Educational Research, 95(2), 110-115.

https://doi.org/10.1080/00220670109596579

Payne, K. J., \& Biddle, B. J. (1999). Poor School Funding, Child Poverty, and Mathematics Achievement. Educational Researcher, 28(6), 4-13. https://doi.org/10.3102/0013189X028006004

Purkey, S. C., \& Smith, M. S. (1985). School Reform: The District Policy Implications of the Effective Schools Literature. The Elementary School Journal, 85(3), 353-389.

Rumberger, R. W., \& Palardy, G. J. (2005). Test Scores, Dropout Rates, and Transfer Rates as Alternative Indicators of High School Performance. American Educational Research Journal, 42(1), 3-42. https://doi.org/10.3102/00028312042001003

Senge, P. (1990). The fifth discipline: The art and practice of the learning organization. New York, NY: Currency, Doubleday.

Skrla, L., McKenzie, K. B., Scheurich, J. J., \& Dickerson, K. (2011). Home-Town Values and High Accountability: A Texas Recipe for Districtwide Success in an Urban School District. Journal of Education for Students Placed at Risk (JESPAR), 16(2), 137-165. https://doi.org/10.1080/10824669.2011.559902

Smylie, M. A. (2009). Continuous School Improvement (1 edition). Thousand Oaks, Calif: Corwin.

Thompson, C. L., Sykes, G., \& Skrla, L. (2008). InstructionallyFocused District Leadership: Toward A Theoretical Account. Retrieved from http://education.msu.edu/epc/forms/Thompson_et_al_2008_Cohe rent_Instructionally_Focused_District_Leadership.pdf

Trujillo, T. (2013). The reincarnation of the effective schools research: rethinking the literature on district effectiveness. Journal of Educational Administration, 51(4), 426-452. https://doi.org/10.1108/09578231311325640

Trujillo, T. (2015) Learning from the past to chart new directions in the study of school district effectiveness. In Daly, A. J., \& Finnigan, K. S. (Eds.). (2016). Thinking and Acting Systemically: Improving School Districts Under Pressure, p.11-48. Washington, DC: Amer Educational Research Assn.

Verstegen, D. A., \& King, R. A. (1998). The Relationship Between School Spending and Student Achievement: A Review and Analysis of 35 Years of Production Function Research. Journal of Education Finance, 24(2), 243-262. 